\title{
Analysis of the Demand of Parents and Teachers for Children's Library*
}

\author{
어린이도서관에 대한 학부모와 교사들의 수요도 조사분석
}

\author{
Hyun-Jin Hong**, Mi Hee Kang***, \\ Mi Bong Jung****, Dae Keun Jeong******
}

\begin{abstract}
The purpose of this study was to examine the demand of parents and teachers for a children's library and analyze the need in consideration of their age and children's library-using frequency. The subjects in this study were 1,500 parents and teachers in the region of Gwangju, on whom a survey was implemented to find out the necessity of a children's library, what should be considered in terms of design and program development and what forms of materials should be provided. As a result of checking their needs for the functions of a library, the parents and teachers investigated attached importance to culture, welfare and hands-on culture/art programs as what a library should focus on. Second, as for design, they gave top priority to comfortableness(sanitary facilities, ventilation, humidity and temperature) and safety(sofas, cushions and carpets for children). Third, as to program preference, both of the parents and teachers considered activity, performance and educational programs necessary among multiple kinds of ongoing programs. Specifically, performance programs ranked first among the parents and third among the teachers. Activity programs ranked first among the teachers and third among the parents. Fourth, concerning the importance of materials possessed by a library, they placed the most emphasis on the kind of materials that could foster creativity and instill the right personality.
\end{abstract}

\section{초 록}

어린이도서관에 대해 학부모와 교사들의 어린이도서관에 대한 수요조사를 시행하였으며, 학부모와 교사들의 연령, 이용빈도 등에 따른 수요조사도 비교분석 하였다. 광주지역의 학부모와 교사 1500 명을 대상으로 설문조사를 수행하였으며, 조사항목은 어린이도서관의 필요기능, 시설설계시 고려사항, 프로그램 개발의 고려사항, 구비할 자료의 형태 등으로 이에 대한 요구도를 파악하고자 하였다. 수요분석결과 첫째, 도서관의 필요기능으로 문화복지기능, 문화예술체험기능 등을 높게 평가하였고, 시설설계에서는 쾌적성(위생시설과 환기, 습도, 온도 등)과 안정성(어린이용 쇼파, 쿠션, 카펫 등)을 최우선시하였으며, 셋째, 프로그램 선호유형으로는 현재 진행되고 있는 다양한 프로그램 중 학부모와 교사 모두 활동, 공연, 교육 프로그램이 필요하다고 응답하였다. 특히 공연 프로그램을 학부모 1순위, 교사 3순위로 꼽았으며, 활동 프로그램은 교사 1 순위, 학부모 3 순위로 조사되었다. 넷째, 도서관에 구비해야할 자료의 중요도로는 창의성을 길러줄 수 있는 자료, 바른 인성을 길러줄 수 있는 자료 등의 중요도를 가장 높게 평가하는 것으로 나타났다.

Keywords: chilren's library, parents need analysis, teachers need analysis 어린이도서관, 학부모 수요조사, 교사 수요조사

* This Research was supported by research fund of Ministry of Culture, Sports and Tourism and Chonnam National University in 2008.

** Professor, Department of Library and Information Science, Chonnam National University (hjhong@chonnam.ac.kr)

*** Lecturer, Department of Library and Information Science, Chonnam National University (mhkang@hanmail.net)

**** Graduate school, Department of Library and Information Science, Chonnam National University (carrel@hanmail.net)

***** Graduate school, Department of Library and Information Science, Chonnam National University (basicwindy@hanmail.net)

- Received : 18 May 2009 - Revised : 26 May 2009 - Accepted : 8 June 2009

- Journal of the Korean Society for Information Management, 26(2): 149-172, 2009. [DOI:10.3743/KOSIM. 2009.26.2.149] 


\section{Introduction}

A children's library is a space where children are provided with good books and culture, where they could improve their knowledge, where they could understand, experience and fit into social environments, and where they could elicit potentials from themselves. As there is a growing need for culture, the importance of children's culture and family culture comes into spotlight in recent days. Specifically, the importance of children's creativity, sociability and community is highlighted in association with children's culture, and they need to have an opportunity to get the right understanding of society involving environments, economy, history and culture.

In highly civilized advanced countries, children's libraries are well equipped enough to offer superb services both in quality and quantity. In our country, however, children's libraries are actually in harsh environ- ments. Lately, the importance of reading and children's libraries is increasingly stressed, and that phenomenon serves to change people's mind-set and to let them wake up to the desperate necessity of children's libraries with great interest.

When it comes to the number of libraries for children only, there were just two national or public children's libraries in Seoul till 2003. But 'the Miracle Library Project' launched in 2003 served as a catalyst in drawing a huge attention from our society to children's libraries. Each region has pushed ahead with the establishment of children's libraries, and the number of the libraries is expected to be gradually on the rise.

There are several forms of children's libraries: children's special libraries, children's rooms of public libraries, private children's libraries, village libraries and elementary school libraries that employ librarians as service providers.

A lot of earlier domestic studies have centered around the state of children's libraries or programs, and few research efforts have ever been directed into the demand of teachers or parents from the perspectives of the users, though those people use children's libraries along with children as their protectors or guardians(Gwak Cheol-wan, 2005; Kang Bo-kyung, 2003). In the event of children's libraries, many users who include infants, preschoolers and lower-grade school children must be accompanied by their parents, and the opinions of parents must be gathered. Likewise, the opinions of teachers should be reflected as well to provide elementary schoolers with good programs in collaboration with their schools and to find out what kinds of facilities they are in want of. As few surveys have been implemented to figure out the demand of parents and teachers for a children's library, this study planned to make a comparative analysis of their perception of and needs for a children's library.

Specifically, the awareness of parents and teachers about the establishment of a special library for children and their needs were checked in the city of Gwangju, since there were no children's special libraries in that area.

The detailed purpose of the study could be de- 
scribed as follows:

1. Examine the perception of parents and teachers about a children's library, their use of children's libraries, their complaints and needs for the function, program, management and facilities of the library.

2. Make a post-hoc analysis to grasp the relationship of the age of parents and teachers and the library-using frequency of parents to their preference for the management form of a children's library, as their preference might hinge on their characteristics.

\section{Method}

A survey was conducted to find out the perception of parents and teachers for a children's library and their needs.

The subjects in this study were 1,500 teachers and parents at elementary schools and early childhood education institutions in the city of Gwangju. 750 teachers were selected from among teachers who took training courses, and 750 parents were selected from among those who attended parent conferences at 13 elementary schools and 13 early childhood education institutions. The teachers and parents were surveyed in person from January 14 to February 1, 2008. The response rate stood at 79.9 percent, and the answer sheets from 1,153 participants who involved 545 parents and 588 teachers were analyzed except 32 incomplete ones.

The questionnaires dealt with experiences and frequency of using children's libraries, complaints, the required functions of a children's library, the management form of it, what should be considered in setting up a children's library and developing programs, spatial construction and the form of materials to be possessed.

Besides, a post-hoc analysis was carried out to see if the age of the parents and teachers and the library-using frequency of the parents made any differences.

\section{Results}

\subsection{Needs Analysis}

The awareness of the parents and teachers in the city of Gwangju about a children's library and their demand were investigated, and then the state of library use and their perception of and needs for the following things were discussed: spatial construction, facility arrangement, programs, collections of books, the operation of manpower, finance, the form of establishment and long-term development plans.

\subsubsection{The State of Children's Library Use}

As for the age distribution of the parents and teachers, 23 parents $(4.0 \%)$ were in their $20 \mathrm{~s}$ or thirty years old, and $384(66.2 \%)$ belonged to the $31-40$ age group. $163(28.1 \%)$ were at the age of 41 to 50 , and $10(1.7 \%)$ were at the age of 51 and up. In the event of the teachers, 298(53.8\%) 
were in their 20 s or thirty years old. $189(34.1 \%)$ were at the age of 31 to 40 , and 57(10.3\%) belonged to the $41-50$ age group. $10(1.8 \%)$ were at the age of 51 and up. Thus, the largest parent group that accounted for $66.2 \%$ was aged between 30 and 40, and approximately 54 percent of the teachers were in their 30 s and down.

As for general characteristics, only the teachers were asked about the grade of children of whom they were in charge, and about 45 percent worked at kindergartens or daycare centers.

The kindergarten and daycare center teachers numbered 253(45\%), and 69 teachers(12.3\%) taught school children in their first and second grades. 82 teachers $(14.6 \%)$ took charge of third and fourth graders, and 152 teachers $(27.0 \%)$ were in charge of fifth and sixth graders. So the largest group that accounted for 45 percent worked at kindergartens and daycare centers.

\section{(1) The Parents}

As showed in $<$ Table 1>, 60.8 percent of the parents had ever used a children's library, and 20.3 percent of them visited a children's library once or more a week. A little more than half(57\%) visited a children's library approximately once a month.

As a result of asking what time would be most convenient for them to visit a children's library with their children, the largest group(25.3\%) chose 2 to 3 p.m., and the second greatest group $(19.4 \%)$ preferred 3 to 4 p.m.(see <Table $2>$ ).

$<$ Table $3>$ indicates that the parents who used a children's library complained most of a shortage of amenities such as a resting room or a suckling room, followed by poor Internet connection and noisy, distractive atmosphere.

〈Table 1〉 Experiences and frequency of using a children's library among the parents

\begin{tabular}{|c|c|c|c|c|c|}
\hline & \multicolumn{2}{|c|}{ Use Experience } & & \multicolumn{2}{|c|}{ Use Frequency } \\
\hline & Frequency & Percentage & & Frequency & Percentage \\
\hline \multirow{2}{*}{ Used } & \multirow{2}{*}{345} & \multirow{2}{*}{60.8} & Once or more a week & 71 & 20.3 \\
\hline & & & Once or more a month & 129 & 36.8 \\
\hline \multirow{2}{*}{ Not used } & \multirow{2}{*}{222} & \multirow{2}{*}{39.2} & Fewer than once a month & 115 & 32.8 \\
\hline & & & Others & 365 & 10.3 \\
\hline Total & 567 & $100.0 \%$ & Total & 351 & $100.0 \%$ \\
\hline
\end{tabular}

〈Table 2〉 The most convenient time for using a children's library among the parents

\begin{tabular}{l|c|c||c|c|c}
\hline & Freq. & $\%$ & & Freq. & $\%$ \\
\hline After 9 to 10 a.m. & 7 & 2.0 & After 2 to 3 p.m. & 90 & 25.3 \\
\hline After 10 to 11 a.m. & 60 & 16.9 & After 3 to 4 p.m. & 69 & 19.4 \\
\hline After 11 to 12 a.m. & 46 & 12.9 & After 4 to 5 p.m. & 27 & 7.6 \\
\hline After 12 a.m. to 1 p.m. & 7 & 2.0 & After 5 to 6 p.m. & 21 & 5.9 \\
\hline After 1 to 2 p.m. & 29 & 8.1 & Total & 356 & $100.0 \%$ \\
\hline
\end{tabular}


〈Table 3〉 The complaints of the parents about children's libraries

\begin{tabular}{l|c|c|c|c}
\hline & Frequency & Mean & $\begin{array}{c}\text { Standard } \\
\text { Deviation }\end{array}$ & Rank \\
\hline A lack of materials such as printed books & 282 & 3.72 & 0.88 & 2 \\
\hline A lack of multimedia materials like e-books or DVDs & 256 & 3.61 & 0.90 & 9 \\
\hline Poor Internet connection and a shortage of computers & 285 & 3.60 & 0.92 & 7 \\
\hline Inadequate amenities like a resting room or suckling room & 289 & 3.79 & 0.92 & 1 \\
\hline Improper maintenance of sanitary facilities like a restroom or washstand & 280 & 3.58 & 1.00 & 8 \\
\hline Narrow spaces(reading and digital rooms) & 279 & 3.64 & 0.93 & 4 \\
\hline Insufficient programs & 274 & 3.72 & 0.91 & 2 \\
\hline Dull and stagnant atmosphere & 271 & 3.63 & 0.95 & 5 \\
\hline Noisy and distractive ambience & 284 & 3.61 & 0.97 & 6 \\
\hline \multicolumn{1}{c|}{ Total } & 2.500 & 3.66 & 0.93 & \\
\hline
\end{tabular}

As shown in $<$ Table $4>$ on the reason why the nonusers didn't use a children's library with their children, 33 percent of the parents felt the need for that, but there were no children's libraries available around their places. 28 percent answered that children's libraries were not easily accessible.

\section{(2) The Teachers}

$<$ Table $3>$ shows that the parents complained most of a shortage of amenities, in terms of the complains of the libraries, the teachers pointed out a lack of multimedia materials as their biggest grievance(a mean of 3.85 out of possible five points), followed by poor Internet connection (3.73). They considered sanitary facilities and atmosphere to be less unsatisfactory.

As shown in $\langle$ Table $5>$, the nonuser teachers didn't use a children's library due to the same reason as that of the parents. 29.6 percent felt the need for that but there were no children's libraries available, and 27.3 percent replied that there was a children's library available but it was not easily accessible.

\subsubsection{Demand for a Children's Library}

(1) The Parents

$<$ Table $6>$ shows that the vast majority of the parents(82.2\%) intended to use a children's library with their children together. As many as 60.8 percent were willing to use a children's library with their children in case of going there together, and approximately 33 percent wanted to use another facility if there would be any within the same building.

As shown in $\langle$ Table $7>$, 88.1 percent of the parents felt the need for family programs in which they could participate with their children at a children's library, and those parents especially placed the most emphasis on the necessity of participatory programs such as movie, exhibition, performance or drama(4.54). They gave the second most weight 
154 Journal of the Korean Society for Information Management, 26(2), 2009

$\langle$ Table 4$\rangle$ The reason why the nonuser parents didn't use a children's library

\begin{tabular}{l|c|c}
\hline & Freq. & $\%$ \\
\hline I don't find it necessary to use a children's library. & 22 & 6.9 \\
\hline I feel the need for that but no children's libraries are available. & 105 & 33.0 \\
\hline There is a children's library available but it's not easily accessible. & 89 & 28.0 \\
\hline $\begin{array}{l}\text { There is a children's library near my house but it's not easy to go there because of my child's } \\
\text { studies. }\end{array}$ & 47 & 14.8 \\
\hline I don”t know the fact that there are children's libraries. & 41 & 12.9 \\
\hline Others & 14 & 4.4 \\
\hline \multicolumn{1}{c}{ Total } & 318 & 100.0 \\
\hline
\end{tabular}

$\langle$ Table 5〉 The reason why the nonuser teachers didn't use a children's library

\begin{tabular}{l|c|c}
\hline & Freq. & $\%$ \\
\hline I don't find it necessary to use a children's library. & 17 & 3.9 \\
\hline I feel the need for that but there's no children's library available. & 128 & 29.6 \\
\hline There is a children's library available but it's not easily accessible. & 118 & 27.3 \\
\hline $\begin{array}{l}\text { There is a children's library around my house but it's not easy to go there due to my child's } \\
\text { studies. }\end{array}$ & 80 & 18.5 \\
\hline I don't know the fact there are children's libraries. & 59 & 13.7 \\
\hline \multicolumn{1}{c}{ Others } & 30 & 6.9 \\
\hline \multicolumn{1}{c|}{ Total } & 432 & 100.0 \\
\hline
\end{tabular}

〈Table 6〉 The parents' intention of visiting a children's library with their children and the use of another facility

\begin{tabular}{|c|c|c|c|c|c|}
\hline Child & Freq. & $\%$ & Parents & Freq. & $\%$ \\
\hline \multirow{5}{*}{$\begin{array}{l}\text { I will go with } \\
\text { my child. }\end{array}$} & \multirow{5}{*}{470} & \multirow{5}{*}{82.2} & I will use another facility within the same building. & 167 & 33.1 \\
\hline & & & I will use the library with my child together. & 307 & 60.8 \\
\hline & & & I will wait in a resting room or lounge. & 9 & 1.8 \\
\hline & & & $\begin{array}{l}\text { I will do something else outside the library while waiting for } \\
\text { my child. }\end{array}$ & 17 & 3.4 \\
\hline & & & Others & 5 & 1.0 \\
\hline $\begin{array}{c}\text { I will let my } \\
\text { child go there } \\
\text { alone. }\end{array}$ & 102 & 17.8 & \multirow[t]{2}{*}{ Total } & \multirow[t]{2}{*}{505} & \multirow[t]{2}{*}{100.0} \\
\hline Total & 572 & 100.0 & & & \\
\hline
\end{tabular}

$\langle$ Table 7$\rangle$ The outlook of the parents on the necessity of family programs and the kinds of their favorite programs.

\begin{tabular}{c|c|c|l|c|c|c|c}
\hline & Freq. & $\%$ & & Freq. & Mean & SD & Rank \\
\hline Necessary & 483 & 88.1 & $\begin{array}{l}\text { Participatory activities like movie, exhibition, } \\
\text { performance or drama }\end{array}$ & 465 & 4.54 & 0.67 & 1 \\
\hline
\end{tabular}




\begin{tabular}{|c|c|c|c|c|c|c|c|}
\hline & & & Reading and writing programs & 432 & 4.32 & 0.78 & 3 \\
\hline & & & Trip to historical sites, excavation and inquiry programs & 427 & 4.16 & 0.88 & 4 \\
\hline & & & Hobby programs like handicraft or photographing & 413 & 3.93 & 0.88 & 6 \\
\hline & & & Culture and after-school programs & 399 & 3.73 & 0.96 & 7 \\
\hline & & & Health and sport activities & 427 & 4.06 & 0.94 & 5 \\
\hline & & & Programs for both children and parents & 443 & 4.36 & 0.77 & 2 \\
\hline Not necessary & 65 & 11.9 & \multirow{2}{*}{ Total } & \multirow{2}{*}{3,006} & \multirow{2}{*}{4.16} & \multirow{2}{*}{0.84} & \\
\hline Total & 548 & 100.0 & & & & & \\
\hline
\end{tabular}

to the sort of programs that parents and children could take part in together(4.36), and reading and writing programs(4.32) were also accentuated a lot.

As shown in $<$ Table $8>$ about top priority for the development of children's library programs, the parents put the most stress on customized programs tailored to children's developmental stage (4.66). 74.2 percent considered those programs very important, and the second largest group emphasized the necessity of participatory programs such as hands-on, inquiry or excavation programs(4.26).

As $<$ Table $9>$ indicates, the parents regarded performance programs as most important(4.40), followed by educational programs, activity programs and family programs. After-school programs were preferred the least, and welfare programs were considered less important.

As shown in $<$ Table $10>$ on the design of a children's library, the parents wanted that to be comfortable, to be sanitary, to be well ventilated and to be well controlled in terms of temperature and humidity. 78.1 percent put stress on comfortableness, as they gave a very high mean of 4.70 to that. The second largest group believed that a children's library should be designed to ensure safety and articulation, namely harmony with surrounding environments. As for safety, a supply of sofa, cushion and carpet for children was accentuated.

As shown in $\langle$ Table $11>$, the parents viewed children's reading rooms as most important among various kinds of rooms in a children's library. 77.4 percent deemed them very important, and reading

〈Table 8> The outlook of parents on top priority for the development of children's library programs

\begin{tabular}{l|c|c|c|c}
\hline & Freq. & Mean & SD & Rank \\
\hline Customized programs suitable for child development stage & 521 & 4.66 & 0.60 & 1 \\
\hline Intriguing programs tailored to client needs & 444 & 4.20 & 0.78 & 3 \\
\hline Programs linked to school curriculum & 471 & 4.20 & 0.82 & 3 \\
\hline Reading and study programs & 473 & 4.20 & 0.82 & 3 \\
\hline Creative programs focusing on investigation, research or participation & 456 & 4.22 & 0.81 & 6 \\
\hline Participatory programs focusing on experience, inquiry and excavation & 487 & 4.26 & 0.83 & 2 \\
\hline \multicolumn{1}{c}{ Total } & 2,852 & 4.29 & 0.78 & \\
\hline
\end{tabular}


$\langle$ Table 9〉 The preference of the parents for children's library programs

\begin{tabular}{l|c|c|c|c}
\hline & Freq. & Mean & SD & Rank \\
\hline Exhibition programs & 440 & 4.10 & 0.79 & 9 \\
\hline Activity programs & 442 & 4.30 & 0.75 & 3 \\
\hline Performance programs & 454 & 4.40 & 0.68 & 1 \\
\hline Educational programs & 447 & 4.39 & 0.70 & 2 \\
\hline Welfare programs & 407 & 4.07 & 0.82 & 10 \\
\hline Family programs & 439 & 4.26 & 0.77 & 4 \\
\hline Inquiry programs & 428 & 4.11 & 0.84 & 8 \\
\hline After-school programs & 422 & 3.90 & 0.93 & 11 \\
\hline English programs & 447 & 4.22 & 0.85 & 5 \\
\hline Traditional culture and art programs & 426 & 4.15 & 0.84 & 7 \\
\hline Hands-on multicultural programs & 438 & 4.20 & 0.87 & 6 \\
\hline \multicolumn{1}{c}{ Total } & 4,790 & 4.19 & 0.80 & \\
\hline
\end{tabular}

$\langle$ Table 10〉 The outlook of the parents on top priority for library design

\begin{tabular}{l|c|c|c|c}
\hline & Freq. & Mean & SD & Rank \\
\hline Articulation(harmony with surrounding environments) & 491 & 4.41 & 0.70 & 3 \\
\hline Efficiency (reasonable size) & 480 & 4.37 & 0.70 & 5 \\
\hline Diversity (a supply of extracurricular activities) & 468 & 4.14 & 0.79 & 7 \\
\hline Aesthetics(proper color and illumination) & 461 & 4.22 & 0.78 & 8 \\
\hline Comfortableness(sanitary facilities, ventilation, humidity and temperature) & 507 & 4.70 & 0.66 & 1 \\
\hline Safety(sofa, cushion and carpet for children) & 493 & 4.65 & 0.63 & 2 \\
\hline Ambience(materials of floor, wall and ceiling) & 475 & 4.44 & 0.73 & 6 \\
\hline Biological features(consideration of children's body shape) & 487 & 4.56 & 0.72 & 4 \\
\hline \multicolumn{1}{c}{ Total } & 3,862 & 4.44 & 0.71 & \\
\hline
\end{tabular}

〈Table 11〉 The outlook of parents on the necessity of children's library rooms

\begin{tabular}{l|c|c|c|c}
\hline & Freq. & Mean & SD & Rank \\
\hline Reading room for children & 508 & 4.70 & 0.61 & 1 \\
\hline Reading room for infants and preschoolers & 436 & 4.23 & 0.86 & 8 \\
\hline Chat room & 449 & 4.10 & 0.83 & 6 \\
\hline Digital room & 462 & 4.24 & 0.77 & 4 \\
\hline Auditorium and multipurpose hall & 439 & 4.00 & 0.83 & 7 \\
\hline Audiovisual room & 459 & 4.21 & 0.78 & 5 \\
\hline Culture room & 480 & 4.32 & 0.72 & 2 \\
\hline Exhibition room & 470 & 4.24 & 0.74 & 3 \\
\hline Play room & 427 & 4.07 & 0.93 & 9 \\
\hline \multicolumn{1}{c|}{ Total } & 4.130 & 4.23 & 0.79 & \\
\hline
\end{tabular}


rooms were considered far more important than the others. The second most important spaces were cultural facilities, followed by exhibition spaces.

As shown in $<$ Table 12>, the largest number of the parents wanted a reading room to be close to bookshelves, and their favorite type of furniture was a table. The second greatest group wanted a reading room to be close to bookshelves, and their favorite type of furniture was a sofa. They gave very small marks to spaces that were closed or far from bookshelves, which were below the average. In particular, about 50 percent didn't like closed spaces.

As shown in $<$ Table $13>$ on preference for typical and multimedia- centered digital libraries, about half of the parents had a liking for a hybrid library, which was a combination of typical and digital libraries. The second most favored library was a multimedia-centered, state-of-the-art digital one.

As shown in $<$ Table $14>$ on the importance of different sorts of materials to be possessed by a children's library, the parents looked upon creativity-fostering materials as most integral, followed by the kind of materials that could encourage children to build up the right personality. As the following graph implies, however, the collective average of all the materials listed was 4.5 , and 50 to 70 percent of the parents regarded each kind of material as very crucial. Therefore it could be said that most of the materials listed were very vital.

〈Table 12〉 The outlook of the parents on the structure of a reading room

\begin{tabular}{l|c|c|c|c}
\hline & Freq. & Mean & SD & Rank \\
\hline Close to bookshelves and equipped with tables & 458 & 4.25 & 0.82 & 1 \\
\hline Close to bookshelves and equipped with sofas & 403 & 3.83 & 0.97 & 2 \\
\hline Big space away from bookshelves & 394 & 3.70 & 0.97 & 3 \\
\hline Small space away from bookshelves & 332 & 2.93 & 1.00 & 5 \\
\hline Closed space separated from bookshelves & 336 & 2.64 & 1.16 & 6 \\
\hline Open space separated from bookshelves & 392 & 3.79 & 1.05 & 4 \\
\hline \multicolumn{1}{c|}{ Total } & 2,315 & 3.52 & 1.00 & \\
\hline
\end{tabular}

〈Table 13〉 The preference of the parents for the form of a library

\begin{tabular}{l|c|c|c}
\hline & Freq. & $\%$ & Rank \\
\hline Typical library with printed media & 50 & 9.3 & 3 \\
\hline Multimedia-centered up-to-date digital library & 142 & 26.5 & 2 \\
\hline Combination of typical and digital libraries & 249 & 46.5 & 1 \\
\hline Typical library furnished with computer labs & 43 & 8.0 & 5 \\
\hline Digital library furnished with basic printed materials & 4 & 0.7 & 6 \\
\hline U-library & 47 & 8.8 & 4 \\
\hline Others & 1 & 0.2 & 7 \\
\hline \multicolumn{1}{c|}{ Total } & 536 & 100.0 & \\
\hline
\end{tabular}


〈Table 14〉 The outlook of the parents on the importance of different kinds of materials to be possessed in a children's library

\begin{tabular}{l|c|c|c|c}
\hline & Freq. & Mean & SD & Rank \\
\hline Intriguing and interesting materials & 483 & 4.36 & 0.76 & 5 \\
\hline Materials tailored to the developmental features of different age groups and stages & 497 & 4.63 & 0.60 & 3 \\
\hline Educational materials & 471 & 4.50 & 0.67 & 4 \\
\hline Materials instilling a good personality & 504 & 4.65 & 0.63 & 2 \\
\hline Creativity-fostering materials & 489 & 4.65 & 0.63 & 1 \\
\hline Materials recommended by experts and professional institutions & 437 & 4.23 & 0.77 & 6 \\
\hline \multicolumn{1}{c|}{ Total } & 2881 & 4.50 & 0.68 & \\
\hline
\end{tabular}

As shown in $<$ Table $15>$ on the necessity of multimedia and electronic materials, the parents viewed educational software as most indispensable, followed by e-books and online media. It indicates that the parents called for a wide variety of online information.

$<$ Table 16> indicates that the vast majority of the parents had a liking for a governance system as the form of a children's library management, which was a collaborative system among the government, mayor and citizens. It implies that the development of a library depends on concerted efforts by the nation, mayor and citizens, not on any particular organization.

As shown in $<$ Table $17>$ on the necessity of multiple functions in a children's library, the parents regarded every function listed as necessary as they gave a mean of 4.38 to all the functions. Especially, they viewed the function of culture and welfare as most integral(4.44 out of possible 5 points), followed by experience of and participation in culture and $\operatorname{art}(4.43)$.

As shown in $<$ Table $18>$ on long-term top priority for the operation of a children's library, the parents regarded a procurement of sufficient budget as what could guarantee a sustained development

〈Table 15〉 The outlook of the parents on the necessity of the utilization of multimedia and electronic materials

\begin{tabular}{|c|c|c|c|c|}
\hline & Freq. & Mean & $\mathrm{SD}$ & Rank \\
\hline E-books & 460 & 4.01 & 0.82 & 2 \\
\hline DVDs & 451 & 4.00 & 0.86 & 4 \\
\hline CD-ROMs & 422 & 3.92 & 0.80 & 6 \\
\hline Audiotapes & 413 & 3.70 & 0.87 & 8 \\
\hline Videotapes & 418 & 3.74 & 0.84 & 7 \\
\hline Online media & 420 & 4.01 & 0.87 & 2 \\
\hline Database & 401 & 3.97 & 0.86 & 5 \\
\hline Educational softwares & 437 & 4.22 & 0.79 & 1 \\
\hline Total & 3422 & 3.95 & 0.84 & \\
\hline
\end{tabular}


〈Table 16〉 The outlook of parents on the form of a children's library management

\begin{tabular}{l|c|c}
\hline & Freq. & $\%$ \\
\hline State-led & 67 & 12.3 \\
\hline Led by local government & 101 & 18.6 \\
\hline Citizen-led & 105 & 19.3 \\
\hline Mayor-led & 14 & 2.6 \\
\hline Governance type(joint system among the nation, mayor and citizens) & 253 & 46.6 \\
\hline Others Total & 3 & 0.6 \\
\hline \multicolumn{1}{c|}{ Th } & 543 & 100.0 \\
\hline
\end{tabular}

$\langle$ Table 17〉 The outlook of the parents on the required functions of a children's library

\begin{tabular}{l|c|c|c|c}
\hline \multicolumn{1}{c|}{ Function } & Freq. & Mean & SD & Rank \\
\hline Culture and welfare & 470 & 4.44 & 0.68 & 1 \\
\hline Cultural community & 460 & 4.35 & 0.70 & 5 \\
\hline Creation of culture and art & 478 & 4.35 & 0.74 & 5 \\
\hline Exchange of knowledge and information & 468 & 4.37 & 0.73 & 4 \\
\hline Backing for school education & 469 & 4.32 & 0.74 & 7 \\
\hline Cultural and artistic experience & 493 & 4.43 & 0.73 & 2 \\
\hline Participation in culture and art & 457 & 4.38 & 0.77 & 3 \\
\hline \multicolumn{1}{c|}{ Total } & 3295 & 4.38 & 0.73 & \\
\hline
\end{tabular}

〈Table 18〉 The outlook of the parents on the long-term management of a children's library

\begin{tabular}{l|c|c|c|c}
\hline & Freq. & Mean & SD & Rank \\
\hline Securing a sufficient budget required for sustained development & 501 & 4.70 & 0.58 & 1 \\
\hline Setting up a professional manpower system & 489 & 4.54 & 0.67 & 3 \\
\hline Developing programs tailored to the age and developmental stage of clients & 492 & 4.55 & 0.66 & 2 \\
\hline Creating the optimum physical environments involving the best spatial construction & 456 & 4.38 & 0.75 & 4 \\
\hline P.R. activities geared toward attracting every possible user & 451 & 4.18 & 0.84 & 5 \\
\hline Preparing multimedia and materials through feedback from users & 445 & 4.27 & 0.78 & 6 \\
\hline Total & 2834 & 4.44 & 0.71 & \\
\hline
\end{tabular}

of the library. 77 percent of the parents viewed it as very necessary, and they put the second most stress on the prolonged development of programs tailored to age and developmental stage.

\section{(2) The Teachers}

Whereas the parents attached the most importance to performance programs, the teachers looked upon activity programs as most vital. followed by educational and performance pro- 
grams(see $<$ Table 19>). More than 60 percent of the teachers regarded the three kinds of programs as very necessary. Like the parents, they viewed English and after-school programs as necessary, but considered them less important than the other programs. However, they gave a mean of 4.34 to all the programs listed, which signified that most of the teachers asked for a variety of programs such as activity, educational, performance and family programs.
Like the opinions of the parents on top priority for the development of children's library programs, more than 83 percent of the teachers regarded customized programs suitable for child developmental stage as very crucial. They gave a very high mean of 4.80 to that, and attached the second most importance to the development of intriguing programs tailored to client needs(see $<$ Table $20>$ ).

As for the top priority for a children's library design, the teachers replied that sofa, cushion and

$\langle$ Table 19〉 The preference of the teachers for different sorts of children's library programs

\begin{tabular}{l|c|c|c|c}
\hline & Freq. & Mean & SD & Rank \\
\hline exhibition programs & 525 & 4.25 & 0.75 & 8 \\
\hline Activity programs & 544 & 4.63 & 0.59 & 1 \\
\hline Performance programs & 545 & 4.52 & 0.71 & 3 \\
\hline Educational programs & 539 & 4.57 & 0.66 & 2 \\
\hline Welfare programs & 525 & 4.34 & 0.73 & 6 \\
\hline Family programs & 537 & 4.47 & 0.71 & 4 \\
\hline Inquiry programs & 526 & 4.23 & 0.77 & 9 \\
\hline After-school programs & 522 & 4.01 & 0.85 & 11 \\
\hline English programs & 519 & 4.02 & 0.92 & 10 \\
\hline Traditional culture and art programs & 536 & 4.39 & 0.77 & 5 \\
\hline Hands-on multicultural programs & 537 & 4.33 & 0.80 & 7 \\
\hline \multicolumn{1}{c}{ Total } & 5.855 & 4.34 & 0.75 & \\
\hline
\end{tabular}

〈Table 20〉 The outlook of the teachers on top priority for the development of children's library programs

\begin{tabular}{l|c|c|c|c}
\hline & Freq. & Mean & SD & Rank \\
\hline Customized programs suitable for child developmental stage & 543 & 4.80 & 0.46 & 1 \\
\hline Intriguing programs tailored to client needs & 534 & 4.62 & 0.59 & 2 \\
\hline Programs linked to school curriculum & 538 & 4.49 & 0.65 & 3 \\
\hline Reading and study programs & 532 & 4.23 & 0.80 & 5 \\
\hline Creative programs focusing on investigation, research and participation & 530 & 4.17 & 0.80 & 6 \\
\hline Participatory programs focusing on experience, inquiry and excavation & 537 & 4.31 & 0.78 & 4 \\
\hline \multicolumn{1}{c}{ Total } & 3,214 & 4.44 & 0.68 & \\
\hline
\end{tabular}


carpet for children should be taken into account in order to ensure the safety of children. 74.8 percent of the teachers found that to be very important. They put the second most emphasis on comfortableness involving sanitation, ventilation, humidity and temperature. Accordingly, both of the teachers and parents gave top priority to safety and comfortableness in terms of a children's library design.

The teachers gave the same answer as the parents to the question which space would be most necessary in a children's library. 85.7 percent of the teachers looked upon children's reading rooms as most crucial, and they attached the second most importance to cultural spaces followed by reading rooms for infants and preschoolers, digital rooms and audiovisual rooms.

In terms of the structure of a children's library reading room, the parents and teachers gave the same answer about the structure of a reading room. The largest group believed that tables should be near by bookshelves, and the second greatest group wanted a reading room to be close to bookshelves and mentioned a sofa as their favorite kind of furniture. In contrast, more than 40 percent didn't prefer closed spaces separated from bookshelves (2.82). Accordingly, the preparation of open reading rooms close to bookshelves are required when a children's library is constructed.

As for the importance of materials to be possessed, the teachers gave top priority to materials tailored to developmental characteristics of different age groups and stages. More than 80 percent considered those materials very vital. The kind of materials that could foster a good personality ranked second. The teachers attached more importance to library materials than the parents since the former gave a mean of 4.63 marks to that. In terms of the utilization of required multimedia and electronic materials, the teachers gave the same answer as the parents, as they deemed educational softwares most necessary. Multimedia materials such as DVDs ranked second. On the contrary, videotapes and audiotapes were considered most unnecessary, but more than 60 percent felt that those tapes should be utilized as well.

In regard to the required function of a children's library, the teachers gave the most weight to a supply of cultural and artistic experiences(see < Table 21>), whereas the parents placed the most stress on the function of culture and welfare. The teachers attached the second most importance to participation in culture, and backing for school education ranked third. The teachers considered backing for school education important in general, while the parents viewed it as the least necessary function. Overall, the majority of the teachers put stress on all the three kinds of functions.

In regard to the required form of a children's library management, both of the parents and teachers sought after the governance system that referred to a collaborative management by the nation, mayor and citizens.

Concerning a long-term top priority for a children's library management, both of the parents and teachers put the most emphasis on a procurement of a sufficient budget required for sustained de- 
$\langle$ Table 21> The outlook of the teachers on the required functions of a children's library

\begin{tabular}{l|c|c|c|c}
\hline \multicolumn{1}{c|}{ Function } & Freq. & Mean & SD & Rank \\
\hline Culture and welfare & 531 & 4.47 & 0.66 & 6 \\
\hline Cultural community & 529 & 4.49 & 0.64 & 4 \\
\hline Creation of culture and art & 528 & 4.38 & 0.71 & 7 \\
\hline Exchange of knowledge and information & 526 & 4.47 & 0.65 & 5 \\
\hline Backing for school education & 535 & 4.51 & 0.67 & 3 \\
\hline Cultural and artistic experience & 540 & 4.61 & 0.62 & 1 \\
\hline Participation in culture and art & 518 & 4.53 & 0.64 & 2 \\
\hline \multicolumn{1}{c|}{ Total } & 3.707 & 4.49 & 0.66 & \\
\hline
\end{tabular}

velopment. 79.8 percent deemed that very vital, and approximately 70 percent of the teachers answered that the prolonged development of customized programs suitable for different ages groups and stages and a professional manpower system were very necessary as well.

\section{(3) The Other Requirements}

The questionnaire gave an open-ended final question by asking the respondents to write down their opinions on or demand for the development of a children's library. They gave a wide variety of replies as follows:

1) The Parents

(1) There should be a separate space for adults, and the kind of programs in which parents and children could be involved together should be provided in order for them to do something with each other. And children should be encouraged to take part in programs without any restraints.

(2) Additional amenities should be installed besides spaces for reading. A children's library should function as a resting space, cultural facility and pleasure resort that are easily available for local citizens.

(3) A lot of programs should be prepared and accessible to children who would the mainstay of our future society, and P.R. activities should be reinforced. Many children should be allowed to benefit from a children's library within the realm of possibility, and everybody should be able to improve his or her knowledge and personality in the library.

(4) A continuing supply of new books should be guaranteed, and users should be able to lend books. Old books that are wornout or torn should be replaced with new ones. As for the selection of books, not only quantity but quality should be taken into account, and the library should serve as a good space open to everybody, not as a stiff or authoritarian public organization.

(5) Character education and cultural experience should be provided, and children should be exposed to various sorts of culture. The library should be run by the government and 
offer a variety of cultural and hands-on activities at a low cost.

(6) Shuttle buses should be provided for children whose houses are distant from the library to be able to use it.

(7) Each region should be equipped with children's special libraries only, and several children's libraries should be constructed to ensure ease of use instead of building big-scale libraries in some particular areas only.

(8) Even the best facility cannot always guarantee user convenience. Employees and volunteers should be friendly and hospitable enough to give satisfaction to users. They should keep in mind that a children's library is an organization that render services, and show every user kindness.

2) The Teachers

(1) Accessibility should be guaranteed to encourage children's frequent visit. Specifically, a supply of shuttle busses is required during vacation to attract more users, and a supply of village busses should be taken into consideration as well. Students from the low-income or double-income families are not likely to be accompanied by their parents even though they want to go to a children's library. Therefore a membership system should be introduced if possible to provide paid members with the shuttle bus service.

(2) It's needed to make a careful preparation for a library to function as a space for diverse kinds of cultural and artistic activities, not just a space for reading. A variety of hands-on programs should be created in consideration of children's interest and developmental stages. A children's library should be interesting and attractive enough so that children could hope to go there everyday. Students should be stimulated to use the library in association with their studies by developing lots of programs linked to school education.

(3) Systematic operating plans should be mapped out, and sustained publicity activities are required to lure more users. For instance, programs related to school education should be prepared.

(4) A procurement of volunteers who read books to children will be effective at attracting students who don't like reading. It would be more advisable to focus on finding volunteer narrators of fairy tales than securing budget for the purchase of videotapes or multimedia. Besides, more programs that narrate fairy tales to students should be supplied.

(5) There should be separate rooms for infants and preschoolers, and different reading rooms should be installed in light of children's age and level. To ensure the success of a children's library, that should serve as a space for adults involving parents and teachers as well, instead of merely focusing on children.

(6) Every district or village should be equipped 
with a children's library, and what matters more is establishing several children's libraries in the same area instead of building a large one, though they are not big in size.

\subsection{Needs Analysis by Age and Use Frequency}

A children's library should be differentiated in accordance with the composition of the user community. So whether the needs of the parents and teachers differed with their age and use frequency was investigated. The largest group of the parents was at the age of 50 and down, who numbered 163(28.1\%), and 10 parents(1.7\%) who were 51 years old or older made up the second biggest age group. As for the teachers, 298 teachers(53.8\%) who were at the age of 30 and down made up the greatest age group, followed by 189 teachers aged between 31 and 40 (34.1\%) and 57 teachers aged between 41 and 50(10.3\%). The fourth biggest group $(10,1.8 \%)$ was 51 years old or older. In other words, the largest number of the parents $(66.2 \%)$ was aged between 30 and 40 , and the greatest number of the teachers(about 54\%) was in their 30s and down.

\subsubsection{The Impacts of Age among the Parents and Teachers}

(1) Family Program Preference by Age

88.1 percent of the parents found family programs to be necessary. As for a favorite type of family program by age, participatory activities such as movie, exhibition, performance or drama ranked first irrespective of age. And every age group considered culture and after-school programs relatively less necessary. The respondents in their 20s had a more liking for health-related sport activities than those in their $50 \mathrm{~s}$, and the respondents in their 20 s and 30s had a bigger preference for programs geared toward both children and parents than those in their 50s. Thus, the younger parents were more fond of dynamic programs like sport or collaborative programs than the older ones.

(2) Preference for the Structure of Reading Room by Age

The parents in their 20s regarded an open reading room separated from bookshelves as the best, and those in their 30s, 40s and 50s had the biggest liking for a reading room close to bookshelves and furnished with tables. A closed reading room separated from bookshelves was the least favorite for those in their $20 \mathrm{~s}$ to $50 \mathrm{~s}$. The respondents in their 20s had the most liking for an open structure, but the other age groups mostly viewed a library as a space for learning. As for the teachers, those in their 20s and 30s had a bigger preference for variable spaces that divided the space with some props or furniture.

(3) Outlook on the Importance of Materials to be Possessed by Age

The parents in their 20s put the most emphasis on materials tailored to developmental character- 
istics of different age groups and stages, followed by creativity-fostering materials. Those in their $30 \mathrm{~s}$ gave a similar answer, since they attached the most importance to creativity- fostering materials, followed by materials tailored to developmental features of different age groups and stages. The parents in their 40 s gave the most weight to materials focusing on a good personality, followed by creativity-fostering materials, and those in their 50s considered intriguing and interesting materials most vital, followed by materials instilling a good personality. Thus, the parents in their $40 \mathrm{~s}$ and $50 \mathrm{~s}$ deemed it more important for children's library materials to center around a good personality than developmental characteristics, and their opinion was contrastive to that of the parents in their $20 \mathrm{~s}$ and $30 \mathrm{~s}$.

The teachers took similar views of materials to be possessed as the parents.

The teachers in their 20s and 30s regarded materials tailored to developmental characteristics of different age groups and stages as most vital, and those in their 40s attached the most importance to materials that could help children build up the right personality. The teachers in their 50s gave the most weight to two kinds of materials that could respectively foster a good personality and creativity. Thus, the older teachers put more value on materials instilling a good personality than another materials tailored to developmental features of different age groups and stages.

(4) Outlook on the Necessity of Children's Library Programs by Age
The parents were asked a question which was most necessary among programs currently provided by children's libraries. The parents in their 20s had the biggest preference for English programs, and those in their 30s had the most liking for performance programs. The parents in their $40 \mathrm{~s}$ and $50 \mathrm{~s}$ were most fond of educational programs.

As for the preference of the teachers, those in their 20 s to 40 s viewed activity programs as most crucial, and the teachers in their 50s considered traditional culture and art programs most vital. As a result of making a post-hoc analysis to find out their opinions on the necessity of the programs, the teachers in their 20s gave more weight to the necessity of English programs than those in their 30 s.

The parents had a more preference for educational programs than the teachers, whereas the latter set higher value on activity programs or traditional culture and art programs.

(5) Outlook on the Necessity of the Utilization of Multimedia and Electronic Materials by Age

Concerning the question which was most necessary among multimedia and electronic materials offered by children's libraries, educational softwares were considered most necessary by the parents in their 30s, 40s and 50s. DVDs ranked first among the respondents in their $20 \mathrm{~s}$.

Out of electronic materials, those in their $20 \mathrm{~s}$, 30s and 40s didn't deemed audiotapes necessary 
a lot, and the respondents in their 50s regarded CD-ROMs as most unnecessary. It denoted that educational softwares and online media took precedence over audiotapes and CD-ROMs.

In the event of the teachers, those in their $20 \mathrm{~s}$ to 40 s viewed educational softwares as the most required electronic materials, and the teachers in their 50s gave top priority to DVDs.

(6) Outlook on the Required Functions of a Children's Library by Age

Among various functions of a children's library, the parents in their 20 s and 30 s set the highest value on the function of culture and welfare. Those in their 40s gave the most weight to cultural and artistic experiences, and the parents in their 50s attached the most importance to backing for school education.

The function of backing for school education was considered most unnecessary by the parents in their 20s and 30s, whereas that ranked first among those in their $50 \mathrm{~s}$. The finding suggested that the younger parents prioritized the function of culture and welfare over that of backing for school education.

In regard to the views of the teachers, they valued cultural and artistic experiences over the other functions irrespective of age. The function of participation in culture and art ranked second among the teachers in their 20s, 30s and 50s, and those in their 40s prized cultural and artistic experiences and exchange of knowledge and information the most, followed by the function of a cultural community.

The findings illustrated that the teachers set the highest value on cultural and artistic experiences among the functions of a library in general, as they had the most preference for performance programs among library programs. In other words, the teachers prized backing for school education as one of the library functions but valued the culture-related experiential functions over it.

\subsubsection{The Impacts of Library-Using Frequency among the Parents}

Whether the library-using frequency of the parents made any differences to their outlook on the necessity of different spaces, their complaints, program preference and view of top priority for the successful long-term operation of a children's library was checked.

60.8 percent of the parents who were surveyed utilized a children's library, and 20.3 percent of those parents visited it once or more a week. 36.8 percent did that once or more a month, and 32.8 percent used it fewer than once a month.

(1) Outlook on the Necessity of Different Spaces by Use Frequency

The users who visited a children's library once or more a week found a children's reading room most necessary, followed by a reading room for infants and preschoolers. Those who visited the library once or more a month attached the most importance to a children's reading room, followed by a culture room, and the parents who used it 
fewer than once a month put the most emphasis on a children's reading room, followed by a culture room. Every parent viewed a children's reading room as most necessary(4.73) irrespective of use frequency. The users who visited a library once or more a week gave the second most weight to the necessity of a reading room for infants and preschoolers, which suggested that the parents who paid a frequent visit to a library utilized a reading room for infants and preschoolers a lot.

(2) Complaints by Use Frequency

What they complained about a children's library they used was examined in consideration of use frequency. Those who used it once a week(3.85) and a month(3.86) complained most of a lack of amenities. Those who used it fewer than once a month were most unsatisfied with a shortage of materials. The parents who used it once or more a month were more dissatisfied with a poor maintenance of sanitary facilities such as a restroom or washstand than those who did it fewer than once a month.

Thus, the parents who used a library more often complained more of a shortage of amenities, and they felt a lot of inconveniences due to that. Accordingly, a children's library should be equipped with plenty of amenities in order for parents and children to use it without any inconveniences.

(3) Program Preference by Use Frequency Out of the programs currently provided by children's libraries, the users who visited them once or more a week viewed performance programs as most necessary, followed by activity programs and educational programs. Those who used them once or more a month valued performance programs most, followed by educational programs. The users who visited them fewer than once a month prized educational programs most, followed by performance programs. Overall, performance and educational programs(4.46) were considered most necessary.

(4) Top Priority for the Successful Long-Term Management of a Children's Library by Use Frequency

As for the importance of things required for the successful management of a children's library on a long-term basis, those who used a library once or more a week attached the most importance to a procurement of professional manpower(4.63), followed by a sufficient budget. The users who visited it once or more a month prized a sufficient budget(4.78) most, followed by professional human resources. Those who used it fewer than once a month gave top priority to a sufficient budget(4.72). The findings illustrated that the users who used a library more frequently were better aware of the importance and necessity of expert personnels as well as budget.

\section{Conclusion and Suggestions}

The survey on demand for a children's library 
showed that approximately 60 percent of the respondents had ever used the library. About 70 percent of the nonusers felt the need for that but there was no children's library available or easily accessible.

This study attempted to find out the demand and requirements of users for a children's library in a move to pave the way for the establishment of a special library for children from which a lot of children and local residents could benefit.

A survey was conducted on parents and teachers to figure out their use of children's libraries and their demand. The findings of the study were as follows:

1) The Use of Children's Libraries

(1) As for experience and frequency of using a children's library, 60.8 percent of the parents had ever used it. Out of the nonuser parents, 33 percent of the parents(29.6 percents of the teachers) felt the need for that but there was no children's library available.

28 percent of the nonuser parents(18 percent of the nonuser teachers) felt the need for a children's library but didn't used it since it was distant from their places.

The findings on the use of children's libraries by the parents and teachers proved the absolute importance of accessibility. A lot of the respondents found it necessary to use a children's library but couldn't do that as there was no library available or easily accessible. The finding justified the desperate necessity of the establishment of more child- ren's libraries. The introduction of shuttle bus service or village buses should be taken into consideration in order for users for whom there's no library available to gain an easier access to that. In particular, children from the low-income classes are unlikely to have access to a library, and more transportation services should be supplied in their behalf. Besides, P.R. activities should be fortified in diverse ways since many parents and teachers couldn't use a children's library due to a lack of information on that.

(2) Complaints about a Children's Library

The parents complained of a shortage of amenities(resting and suckling rooms) and materials(printed books), and the teachers were discontented with a lack of multimedia materials (e-books and DVDs), poor Internet connection and a shortage of computers. As to complaints by use frequency, the users who used a children's library more often were more dissatisfied with a shortage of amenities. Therefore a children's library must be furnished with resting, cultural and convenience facilities to ensure ease of use, and a supply of those facilities must be considered when a library is designed.

2) Demand for the Management of a Children's Library

(1) The parents had the biggest preference for a hybrid children's library, which was a combination of traditional and state-of-the-art multimedia libraries. Their preference should be taken into account when operating plans are devised, and how 
to create a full-fledged hybrid library should be studied.

(2) As for the operation hours of a children's library, it was most convenient for the parents to use it at 2 to 4 p.m. A sufficient number of personnels should serve users during the hours, and a wide variety of programs and activities should be provided for parents to do something with their children together.

(3) In regard to the selection of materials to be possessed, the parents had a liking for the kinds of materials that would be appropriate for the developmental characteristics of different age groups and stages or could stimulate children to improve creativity or build up their character. Unlike those in their 20s and 30s, the parents in their 40s and 50s prioritized personality-building materials over others tailored to developmental features. Likewise, the older teachers put more value on personalitybuilding materials. Accordingly, a children's library should be equipped with materials that are creative and focus on personality in light of developmental stages rather than stereotyped or exciting ones. And intriguing programs should be supplied for children to boost their creativity and have a good personality.

(4) As to the form of a children's library management, both of the parents and teachers believed that the nation, citizens and mayor should join forces. When a special library for children is constructed by the government, all the parties concerned should make concerted efforts to ensure successful management.

(5) Concerning the functions of a children's li- brary, 90 percent of the respondents deemed it necessary for that to serve as a culture and welfare provider, to serve as a cultural community, to create culture and art, to facilitate interchange of knowledge and information, to back up school education, to offer cultural and artistic experiences, and to let children participate in culture and art. By age, the younger parents put the function of culture and welfare above that of backing for school education. In the event of the teachers, every age group set the highest value on the function of cultural and artistic experiences. The teachers prized the function of backing for school education, but they seemed to give more weight to the functions of cultural and artistic experiences and participation. The findings suggested some of the right directions for a children's library. That is, the library should provide various kinds of culture-related hands-on programs.

(6) As for the necessity of a long-term roadmap for the library, both of the parents and teachers found it necessary to secure a sufficient budget to ensure sustained development on a long-term basis, and they put stress on the development of programs tailored to different age groups and stages as well. When their library-using frequency was taken into consideration, those who used a library more often were better cognizant of the importance and necessity of budget and professional human resources. Therefore, a state-led children's library should be assisted to have a sufficient budget in pursuit of sustained development, and should serve as a special library for children only by keeping on securing expert personnels and developing di- 
verse programs in response to their needs.

3) User Demand for the Spatial Construction of a Children's Library

(1) The respondents considered it most advisable for a children's library to be variable by using props or furniture for the division of spaces. By age, the parents in their 20 s had a more preference for an open structure than the other age groups. Similarly, the teachers in their 20 s and 30 s preferred a variable spatial construction than the other age groups. Their preference must be reflected when a children's library is designed. In a word, a children's library should be open and variable enough to make a lot of changes in case of need.

(2) In terms of design, they gave top priority to comfortableness and safety. Children's biorhythm must be taken into account when sanitary facilities, ventilation equipment, humidity and temperature are selected or determined, and the kinds of furniture that ensure safety should be prepared such as sofa, cushion and carpet. Everything should be designed from children's perspective to minimize the occurrence of safety accidents.

(3) As for facility arrangement in a children's library, they consented to the necessity of every space listed in this study, which involved a children's reading room, reading room for infants and preschoolers, chat room, digital room, auditorium, multipurpose hall, audiovisual room, culture classroom, exhibition space and play room. They gave a mean of 4.0 or more to every facility. In particular, both of the parents and teachers attached the most importance to a children's room, followed by a culture room. The two groups respectively gave a mean of 4.70 and 4.84 to the necessity of a children's reading room as the most mandatory space.

In regard to the view of the parents by age, every parent felt the most need for a children's reading room irrespective of use frequency. Those who used a children's library once a more a week put the second most stress on the necessity of a reading room for infants and preschoolers, which implies that the parents used a reading room for infants and preschoolers a lot. As a children's library is a place where children and their guardians use together, it should be designed to address all their needs. A wide variety of programs and spaces should be prepared to let parents accompanying their children spend time in a meaningful way without being bored or tedious. A children's library should turn into a dynamic place for both children and adults by providing special spaces for adults involving parents and researchers.

(4) Concerning the structure of a children's reading room, both of the parents and teachers believed that it must be close to bookshelves, and they had a liking for tables rather than sofas among different sorts of furniture. A separation of reading room from bookshelves or a closed spatial construction should be avoided. For children, there is yet no clear distinction between work and play, and they spend time doing diverse kinds of play. So the sorts of spaces where special educational programs added by play can be conducted should be installed. 
4) User Demand for Children's Library Programs

(1) More than 80 percent of the parents were willing to visit a special library for children with their children if there would be any. They intended to use the library with their children together without leaving them alone, and 88 percent felt the need for family programs. Accordingly, family programs in which children and their families could be involved should be developed when management strategies are mapped out.

(2) Regarding top priority for the development of children's library programs, both of the teachers and parents put emphasis on customized programs tailored to developmental stages. Therefore various kinds of programs should be prepared, which respectively cater to infants, preschoolers, lower-grade school children, upper-grade elementary schoolers, disabled children and children from multicultural families. Every program should be intriguing enough to spark children's interest.

(3) As to program preference, both of the parents and teachers considered activity, performance and educational programs necessary among multiple kinds of ongoing programs. Specifically, performance programs ranked first among the parents and third among the teachers. Activity programs ranked first among the teachers and third among the parents. Educational programs ranked second in both groups. Thus, the importance of performance programs was accentuated once again, and educa- tional programs linked to school curriculum were mandatory as well.

This study made a comparative analysis of the perception of parents and teachers and their needs since few studies have ever centered around their demand for a children's library. In terms of region, Gwangju that was devoid of children's special libraries was selected, and the parents and teachers from this region were surveyed to find out their awareness of and demand for a children's library.

The sustained development of a children's library basically hinges on how much local residents use it with interest, and that should consequently serve as a place to address their cultural needs. That is, a children's library should be region-specific and build a network with domestic and foreign communities to seek after cultural interchange, and that should enable users to acquire knowledge and information, to receive education, to be exposed to culture, to communicate with one another in pursuit of interchange, and to take part in various hands-on activities.

The local range of this study is limited to Kwang-Ju, so, in the future, research efforts should be channeled into checking the view and demand of different local communities and finding out how to satisfy their needs in order for a children's library to function as a hub of local culture in response to local needs. 


\section{References}

Kang, B. K. 2003. Investigation into the perception of parents on the use of children's libraries and their needs. Sungkyunkwan University Graduate School of Education.

Kim, J. W. 2004. A study on the use of children's books in public libraries. Ewha Women's University Graduate School.

Kim, M. R., S. Y. Kim, O. S. Kim, and Y. J. Kim. 2003. "A study on the management and improvement of children's rooms in public libraries." Journal of Library and Information Science, 29: 119-146.

Kwak, C. W. and J. M. Lee. 2005. "A study on the spatial planning of a children's library: awareness of children and parents." Journal of Korean Library \& Information Science Society, 36(4): 155-176.

Lu, Ya-Ling. 2005. How children's librarians help children cope with daily life: An enhanced readers' advisory service. Ph.D. diss., University of California.
Martinez, Gilda. 2005. Libraries, families, and schools. Partnership to achieve reading readiness: A multiple case study of Maryland public librarians. Ph.D. diss., The Johns Hopkins University.

Massey, S. A., A. C. Weeks, and T. Y. Neely. 2005. "Providing Library Services for Urban Children: Challenges and Strategies." Advances in Librarianship, 2: 73-98.

Sullivan, Michael. 2005. Fundamentals of children's services. Chicago: American Library Association.

Sullivan, Michael. 2007. The basis of service for children: how to boost the capabilities of librarians for children. trans. Seoul: The National Library for Children and Young Adults.

Wilson, Patricia J, and Leslie, Roger. 2001. Premiere events: library programs that inspire elementary school patrons. Englewood, Colo: Libraries Unlimited. 